\title{
A pan-Theileria FRET-qPCR survey for Theileria spp. in ruminants from nine provinces of China
}

\author{
Yi Yang ${ }^{1}$, Yongjiang Mao ${ }^{2}$, Patrick Kelly ${ }^{3}$, Zhangpin Yang ${ }^{2}$, Lu Luan', Jilei Zhang ${ }^{1}$, Jing Li', \\ Heba S El-Mahallawy ${ }^{1,4}$ and Chengming Wang ${ }^{1 *}$
}

\begin{abstract}
Background: Theileria spp. are tick transmitted protozoa that can infect large and small ruminants causing disease and economic losses. Diagnosis of infections is often challenging, as parasites can be difficult to detect and identify microscopically and serology is unreliable. While there are PCR assays which can identify certain Theileria spp., there is no one PCR that has been designed to identify all recognized species that occur in ruminants and which will greatly simplify the laboratory diagnoses of infections.
\end{abstract}

Methods: Primers and probes for a genus-specific pan-Theileria FRET-qPCR were selected by comparing sequences of recognized Theileria spp. in GenBank and the test validated using reference organisms. The assay was also tested on whole blood samples from large and small ruminants from nine provinces in China.

Results: The pan-Theileria FRET-qPCR detected all recognized species but none of the closely related protozoa. In whole blood samples from animals in China, Theileria spp. DNA was detected in 53.2\% of the sheep tested (59/111), $44.4 \%$ of the goats $(120 / 270)$ and $30.8 \%$ of the cattle $(380 / 1,235)$. Water buffaloes $(n=29)$ were negative.

Sequencing of some of the PCR products showed cattle in China were infected with T. orientalis/T. sergenti/T. buffeli group while T. ovis and T. luwenshuni were found in sheep and T. luwenshuni in goats. The prevalence of Theileria DNA was significantly higher in Bos p. indicus than in Bos p. taurus (77.7\% vs. 18.3\%) and copy numbers were also significantly higher ( $10^{4.88}$ vs. $10^{3.00}$ Theileria $18 \mathrm{~S}$ rRNA gene copies/per $\mathrm{ml}$ whole blood).

Conclusions: The pan-Theileria FRET-qPCR can detect all recognized Theileria spp. of ruminants in a single reaction. Large and small ruminants in China are commonly infected with a variety of Theileria spp.

Keywords: Theileria spp, FRET-qPCR, Prevalence, Ruminants

\section{Background}

Theileria spp. are tick-transmitted, intracellular protozoan parasites infecting leukocytes and erythrocytes of wild and domestic large and small ruminants. Several Theileria spp., transmitted by ixodid ticks of the genera Rhipicephalus, Hyalomma, Amblyomma and Haemaphysalis, have been described in cattle, water buffaloes, sheep and goats in different geographical zones of the world [1-5]. Theileriosis is primarily limited to tropical and sub-tropical areas of the world, with infections mainly reported in Africa and the Middle East but also in southern Europe and northern Asia

\footnotetext{
* Correspondence: wangcm@yzu.edu.cn

'Jiangsu Co-innovation Center for the Prevention and Control of Important Animal Infectious Diseases and Zoonoses, Yangzhou University College of Veterinary Medicine, Yangzhou 225009, Jiangsu, China

Full list of author information is available at the end of the article
}

[6-11]. Infections by Theileria spp. can cause fever, anemia and hemoglobinuria and, in severe cases, death although many species are benign. Animals recovered from acute or primary infections usually remain persistently infected and may act as reservoirs of infecting ticks $[12,13]$.

While there have been numerous reports of theileriosis in various animal species in China since 1958 [14-27], many have been reported in Chinese and some were based on microscopic detection of parasites which can be difficult with low parasitemia and does not allow ready differentiation of species. Serological studies, although sensitive and easy to perform, are not specific as there is cross reactivity between Theileria spp. Although molecular studies have been performed, these have been to detect Theileria of specific domestic animal species, for example sheep and goats [27]. There have been no 
highly sensitive and specific molecular methods described which enable studies on various animals from widely divergent areas of China where different Theileria spp. might occur. To address this problem, we developed and validated a highly sensitive genus-specific Theileria FRETqPCR that detects the recognized Theileria spp. of domestic animals and investigated the molecular prevalence of Theileria in cattle, water buffaloes, goats and sheep from nine provinces in China.

\section{Methods}

\section{Animals and blood collection}

Between 2007 and 2013, whole blood samples (around $6 \mathrm{ml}$ ) were collected in EDTA from apparently healthy cattle $(n=1,235)$, water buffaloes (29), goats (270) and sheep (111) from 9 provinces/municipality of China (Table 1). The Bos primigenius (p.) taurus studied $(\mathrm{n}=975)$ were Holsteins, Simmentals, Bohai blacks, Luxis and Wannans while the Bos. $p$. indicus $(\mathrm{n}=260)$ were the Yunlings, Minnans, and Leiqiongs (Table 1). The water buffaloes, goats and sheep in the study were bred in China and were indigenous breeds. Gender information was available for cattle from Yunnan province. After collection, the blood samples were frozen at $-20^{\circ} \mathrm{C}$ and shipped on ice (over 2 days) to Yangzhou University where they were frozen at $-80^{\circ} \mathrm{C}$ until thawed at room temperature for DNA extraction as described below. This study was reviewed and approved by the Institutional Animal Care and Use Committee of Yangzhou University and animal owners gave written permissions for blood collection.

\section{DNA extraction}

DNA was extracted from whole blood samples using a standard phenol-chloroform method previously described [28]. Two ml whole blood was used to extract DNA which was resuspended into $200 \mu \mathrm{l} 1 \times \mathrm{T}_{10} \mathrm{E}_{0.1}$ buffer. The concentration of the extracted DNA was established with a Microscale Ultraviolet Spectrophotometer. Negative controls consisting of sterile molecular grade water were used to detect cross- contamination during DNA extraction and processing. The HMBS-based FRET-PCR was performed to verify if the extracted DNAs from blood samples were appropriate for molecular detection of tick-borne pathogens $[29,30]$.

\section{Theileria spp. FRET-qPCR}

\section{Primers and probes}

The 18S rRNA sequences for the available recognized Theileria spp. on GenBank and 4 other closely related protozoan species were obtained from GenBank: $T$. orientalis (HM538222), T. buffeli (HQ840967), T. annulata (KF429799), T. sergenti (EU083804), T. luwenshuni (JX469527), T. velifera (AF097993), T. ovis (AY508458), T. parva (L02366), T. uilenbergi (JF719835), T. equi (AB515310), T. lestoquardi (JQ917458), T. separata (AY260175), T. capreoli (AY726011), T. cervi (AY735119), T. bicornis (AF499604), T. taurotragi (L19082), T. mutans (FJ213585); Babesia bovis (KF928529), B. divergens (LK935835), B. bigemia (LK391709), Hepatozoon americanum (AF176836), Cytauxzoon felis (AY679105) and Toxoplasma gondii (L37415) (Figure 1). The Clustal Multiple Alignment Algorithm was used to identify a highly conserved

Table 1 Molecular prevalence of Theileria spp. in cattle, water buffalo, goat and sheep

\begin{tabular}{|c|c|c|c|c|c|c|c|}
\hline \multirow{3}{*}{$\begin{array}{l}\text { Animal species } \\
\text { Cattle }(n=1235)\end{array}$} & \multirow{2}{*}{\multicolumn{2}{|c|}{ Subspecies /breed }} & \multirow{3}{*}{$\begin{array}{l}\text { Province } \\
\text { Inner Mongolia }\end{array}$} & \multirow{3}{*}{$\begin{array}{l}\text { City } \\
\text { Chifeng }\end{array}$} & \multirow{3}{*}{$\begin{array}{l}\begin{array}{l}\text { Coordinate } \\
\text { of city }\end{array} \\
42.17^{\circ} \mathrm{N}, 118.58^{\circ} \mathrm{E}\end{array}$} & \multicolumn{2}{|c|}{ Theileria positivity } \\
\hline & & & & & & \multirow{2}{*}{$\begin{array}{l}\text { positive /total } \\
19 / 132\end{array}$} & \multirow{2}{*}{$\frac{\%}{14.49}$} \\
\hline & Bos p. taurus & Simmental & & & & & \\
\hline & & Bohai black & Shandong & Binzhou & $37.22^{\circ} \mathrm{N}, 118.02^{\circ} \mathrm{E}$ & $4 / 66$ & $6.1 \%$ \\
\hline & & Luxi & Shandong & Jining & $35.23^{\circ} \mathrm{N}, 116.33^{\circ} \mathrm{E}$ & $40 / 40$ & $100 \%$ \\
\hline & & Holstein & Jiangsu & Yancheng & $33.22^{\circ} \mathrm{N}, 120.08^{\circ} \mathrm{E}$ & $72 / 321$ & $22.4 \%$ \\
\hline & & Holstein & Jiangsu & Yangzhou & $32.23^{\circ} \mathrm{N}, 119.26^{\circ} \mathrm{E}$ & $17 / 144$ & $11.8 \%$ \\
\hline & & Holstein & Shanghai & Shanghai & $31.14^{\circ} \mathrm{N}, 121.29^{\circ} \mathrm{E}$ & $9 / 255$ & $3.5 \%$ \\
\hline & & Wannan & Anhui & Wuhu & $31.19^{\circ} \mathrm{N}, 118.22^{\circ} \mathrm{E}$ & $17 / 17$ & $100 \%$ \\
\hline & Bos p. indicus & Yunling & Yunnan & Kunming & $25.04^{\circ} \mathrm{N}, 102.42^{\circ} \mathrm{E}$ & $124 / 161$ & $77.0 \%$ \\
\hline & & Minnan & Fujian & Putian & $24.26^{\circ} \mathrm{N}, 119.01^{\circ} \mathrm{E}$ & $4 / 25$ & $16.0 \%$ \\
\hline & & Leiqiong & Hainan & Haikou & $20.02^{\circ} \mathrm{N}, 110.20^{\circ} \mathrm{E}$ & $74 / 74$ & $100 \%$ \\
\hline Water buffalo $(n=29)$ & Haizi & & Jiangsu & Yancheng & $33.22^{\circ} \mathrm{N}, 120.08^{\circ} \mathrm{E}$ & $0 / 29$ & $0 \%$ \\
\hline \multirow[t]{2}{*}{ Goat $(n=270)$} & Xinjiang & & Xinjiang & Urumqi & $43.45^{\circ} \mathrm{N}, 87.36^{\circ} \mathrm{E}$ & $4 / 98$ & $4.1 \%$ \\
\hline & Yangtse River & ta White & Jiangsu & Yangzhou & $32.23^{\circ} \mathrm{N}, 119.26^{\circ} \mathrm{E}$ & $116 / 172$ & $67.4 \%$ \\
\hline \multirow[t]{2}{*}{ Sheep $(n=111)$} & Wuranke & & Inner Mongolia & Xilingol & $43.57^{\circ} \mathrm{N}, 116.03^{\circ} \mathrm{E}$ & $36 / 72$ & $50.0 \%$ \\
\hline & Sishui Fur & & Shandong & Jining & $35.23^{\circ} \mathrm{N}, 116.33^{\circ} \mathrm{E}$ & $23 / 39$ & $59.0 \%$ \\
\hline
\end{tabular}




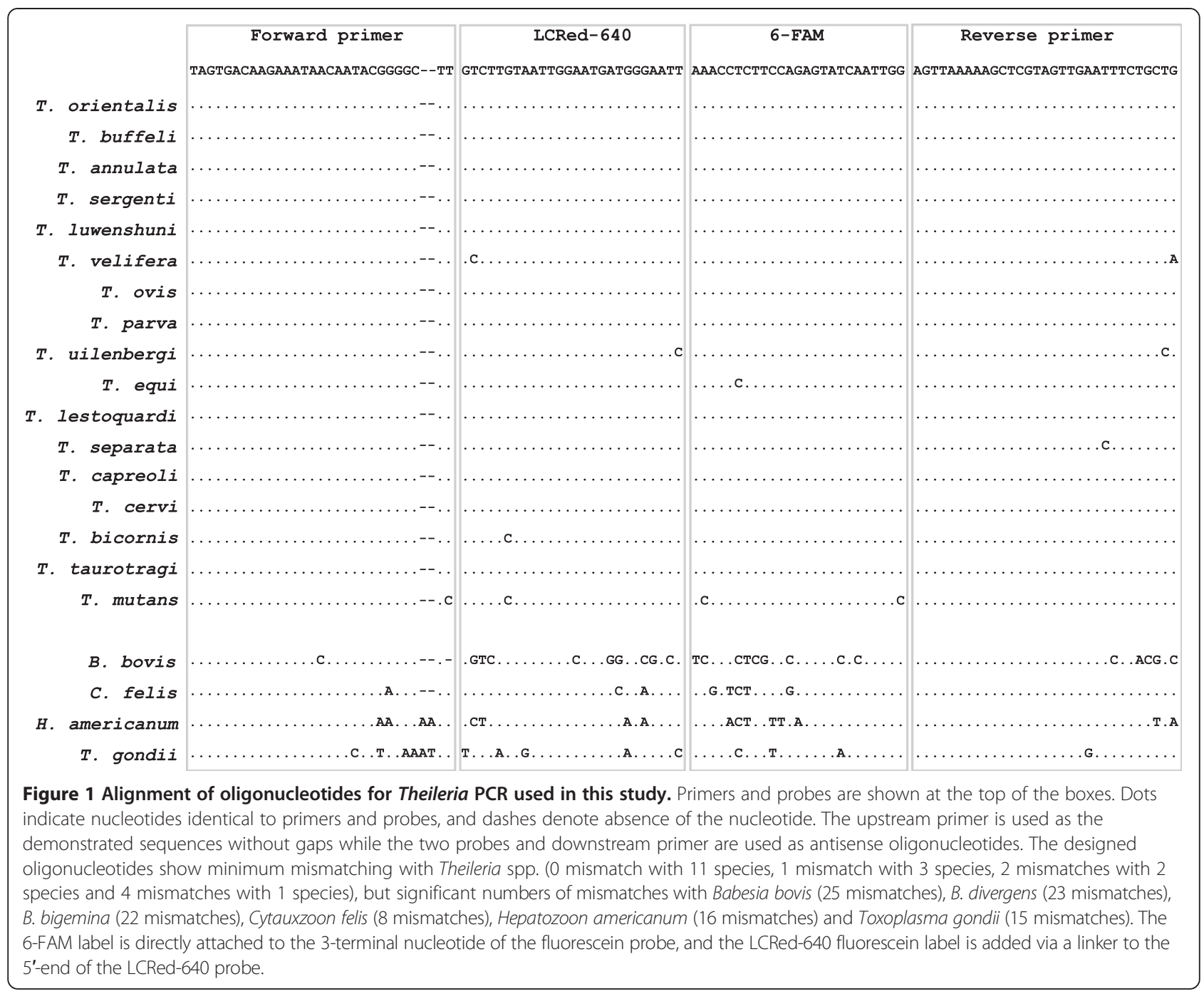

region of the $18 \mathrm{~S}$ rRNA gene common to all the above Theileria spp. but significantly different from the other protozoan species (Figure 1). The primers and probes we developed were situated within the conserved region and synthesized by Integrated DNA Technologies (Coralville, IA, USA). The Theileria FRET-qPCR we established amplifies a 149-bp target with the positions of primers and probes shown in Figure 1: forward primer: 5 '-TAGTGACAAGAAATAACAATACGGGGCT T-3'; reverse primer: 5'-CAGCAGAAATTCAACTAC GAGCTTTTTAACT-3'; anchor probe: 5' -CCAATTG ATACTCTGGAAGAGGTTT-(6-FAM)-3'; reporter probe: 5' -(LCRed640)-AATTCCCATCATTCCAATTACAAGACphosphate-3'.

\section{Thermal cycling}

The Theileria FRET-PCR was performed in a LightCycler $480^{\circ}$ II real-time PCR platform with $20 \mu \mathrm{l}$ volumes comprising $10 \mu \mathrm{l}$ reaction master mix and $10 \mu \mathrm{l}$ of sample. Thermal cycling consisted of a 2 min denaturation step at $95^{\circ} \mathrm{C}$ followed by 18 high-stringency step-down thermal cycles, 40 low-stringency fluorescence acquisition cycles, and melting curve determination between $38^{\circ} \mathrm{C}$ and $80^{\circ} \mathrm{C}$. The parameters for $\mathrm{qPCR}$ were $6 \times 12 \mathrm{sec}$ at $64^{\circ} \mathrm{C}, 8 \mathrm{sec}$ at $72^{\circ} \mathrm{C}, 0 \mathrm{sec}$ at $95^{\circ} \mathrm{C} ; 9 \times 12 \mathrm{sec}$ at $62^{\circ} \mathrm{C}$, $8 \mathrm{sec}$ at $72^{\circ} \mathrm{C}, 0 \mathrm{sec}$ at $95^{\circ} \mathrm{C} ; 3 \times 12 \mathrm{sec}$ at $60^{\circ} \mathrm{C}, 8 \mathrm{sec}$ at $72^{\circ} \mathrm{C}, 0 \mathrm{sec}$ at $95^{\circ} \mathrm{C} ; 40 \times 8 \mathrm{sec}$ at $54^{\circ} \mathrm{C}$ and fluorescence acquisition, $8 \mathrm{sec}$ at $72^{\circ} \mathrm{C}, 0 \mathrm{sec}$ at $95^{\circ} \mathrm{C}$.

\section{Specificity}

PCR products were verified using electrophoresis (1.5\% MetaPhor agarose gels), followed by purification with a QIAquick PCR Purification Kit (Qiagen, Valencia, CA, USA) and genomic sequencing (GenScript, Nanjing, Jiangsu, China). The sequencing data from randomly selected positive Theileria samples $(n=37)$ were compared with 
the existing Theileria sequences in the GenBank using BLAST. The specificity of the PCR was further verified with the amplification of $T$. orientalis rRNA-containing pIDTSMART cloning Vector (Integrated DNA Technologies, Coralville, IA, USA) and 100 DNA copies of the rRNA gene of B. canis, $H$. americanum, C. felis and T. gondii (kindly provided by the parasitological laboratory of Yangzhou University College of Veterinary Medicine).

\section{Sensitivity}

For use as quantitative standards, the PCR products of DNAs of 5 Theileria species (T. orientalis, T. sergenti, T. buffeli, T. luwenshuni, T. ovis) were gel purified using a QIAquick Gel Extraction Kit (Qiagen, Valencia, CA, USA). After using the estimated molecular mass of the rRNA gene and the Quanti-iT TM PicoGreen ${ }^{\circledR}$ dsDNA Assay Kit (Invitrogen Corporation, Carlsbad, CA, USA) to calculate the molarity of the solution, dilutions were made to give solutions containing 10,000, 1,000, 100, 10, 1 gene copies per PCR reaction system. These dilutions, and further dilutions providing 2, 4, 6 and 8 gene copies per PCR reaction, were used to determine the minimal detection limit. The 10-fold dilutions were used as quantitative standards in the FRET-PCR surveys to enable standard curves to be developed for the calculation of the gene copy numbers in positive samples.

\section{Identification of Theileria spp. by PCR and sequencing}

The amplicon of the pan-Theileria FRET-qPCR we established has a sequence which is highly conserved among the different Theileria species. To differentiate Theileria spp. in a positive reaction, we used a standard PCR to amplify a highly polymorphic region of the 18S rRNA gene (591-594 nucleotides for different Theileria spp.) and sequenced the products (GenScript, Nanjing, Jiangsu, China). For the PCR we designed a forward primer $\left(5^{\prime}\right.$-CCTGAGAAACGGCTACCACAT CT-3') that amplified all Theileria species and used a previously described reverse primer ( $5^{\prime}$-GGACTACGA CGGTATCTGATCG-3') that also amplified all species [31].

\section{Statistical analysis}

Differences in positivity of Theileria spp. were analyzed by Chi-squared Test while numbers of copies of the Theileria 18S rRNA gene determined in the Theileria FRET-qPCR were log10-transformed and analyzed using the Student's T-test. Differences of $P<0.05$ were considered statistically significant.

\section{Results}

\section{Development of the pan-Theileria FRET-PCR}

Comparison of the sequences in the highly conserved region of the Theileria spp. we used showed the region is highly conserved, but is substantially different from those in closely related protozoan species (Figure 1). The two primers and two probes we chose for the panTheileria FRET-qPCR had 0-4 nucleotide mismatches with the Theileria spp. in GenBank, but had 25, 23, 22, 8, 16 and 15 mismatches with B. bovis, B. divergens, B. bigemina, C. felis, H. americanum and T. gondii, respectively (Figure 1). The specificity of the pan-Theileria FRETPCR was further confirmed when it gave positive reactions with the $T$. orientalis control, but gave negative reactions with DNAs of $B$. canis, C. felis, H. americanum and T. gondii. The pan-Theileria FRET-qPCR had a specific melting curve $\left(T_{\mathrm{m}} 57.5^{\circ} \mathrm{C}\right)$ with Theileria spp. DNA. Using the gel-purified PCR products as quantitative standards, we determined the detection limit of the pan-Theileria FRET-qPCR was 2 copies of the Theileria $18 \mathrm{~S}$ rRNA gene per reaction for T. orientalis, T. sergenti and T. luwenshuni, T. buffeli and T. ovis.

\section{Prevalence of Theileria spp. DNA in ruminants}

Animals positive for Theileria were found in each of the nine provinces sampled with several animals of each species being positive at each location, except in the case of water buffaloes which were all negative in the one site they were studied. The overall prevalences of Theileria spp. DNA in sheep $(53.2 \% ; 59 / 111)$ and goats $(44.4 \%$; $120 / 270)$ were significantly higher than in cattle $(30.8 \%$; 380/1,235) (two-tailed Chi-squared Test, $P<10^{-4}$ ). The pan-Theileria FRET-PCR showed that sheep had an average of $10^{2.4}$ copies of Theileria $18 \mathrm{~S}$ rRNA/ml whole blood which was significantly lower than the $10^{4.3}$ copies in cattle and $10^{5.8}$ copies in goats (Student's t Test, $P<10^{-4}$ ). While the prevalence of Theileria spp. DNA varied greatly from $3.5 \%(9 / 255)$ in Holsteins from Shanghai to $100 \%$ in Luxi cattle from Shandong (40/40) and Leiqiong cattle from Hainan (74/74), the prevalence did not differ significantly in sheep from Inner Mongolia and Shandong (Table 1, Figure 2).

Sequencing of 87 randomly selected amplicons (52 from cattle, 14 from goats and 21 from sheep) from Theileria DNA positive samples showed that T. orientalis/ T. sergenti/T. buffeli group [29] were present in cattle while T. luwenshuni was found in goats in Jiangsu province and T. ovis and T. luwenshuni in sheep from Inner Mongolia and Jiangsu province, respectively.

\section{Factors associated with the occurrence of theileriosis in cattle}

When we analyzed factors that might be associated with the prevalence of Theileria spp. DNA in cattle we found that Bos $p$. indicus animals had significantly higher positivity $\left(77.7 \%\right.$ vs. $\left.18.3 \% ; P<10^{-4}\right)$ and copy number of the Theileria $18 \mathrm{~S}$ rRNA gene $\left(10^{4.81}\right.$ vs. $10^{3.73}$ copies/per ml whole blood; $P<10^{-4}$ ) than Bos $p$. taurus animals. Similarly, Bos $p$. indicus cattle were more likely to be positive 


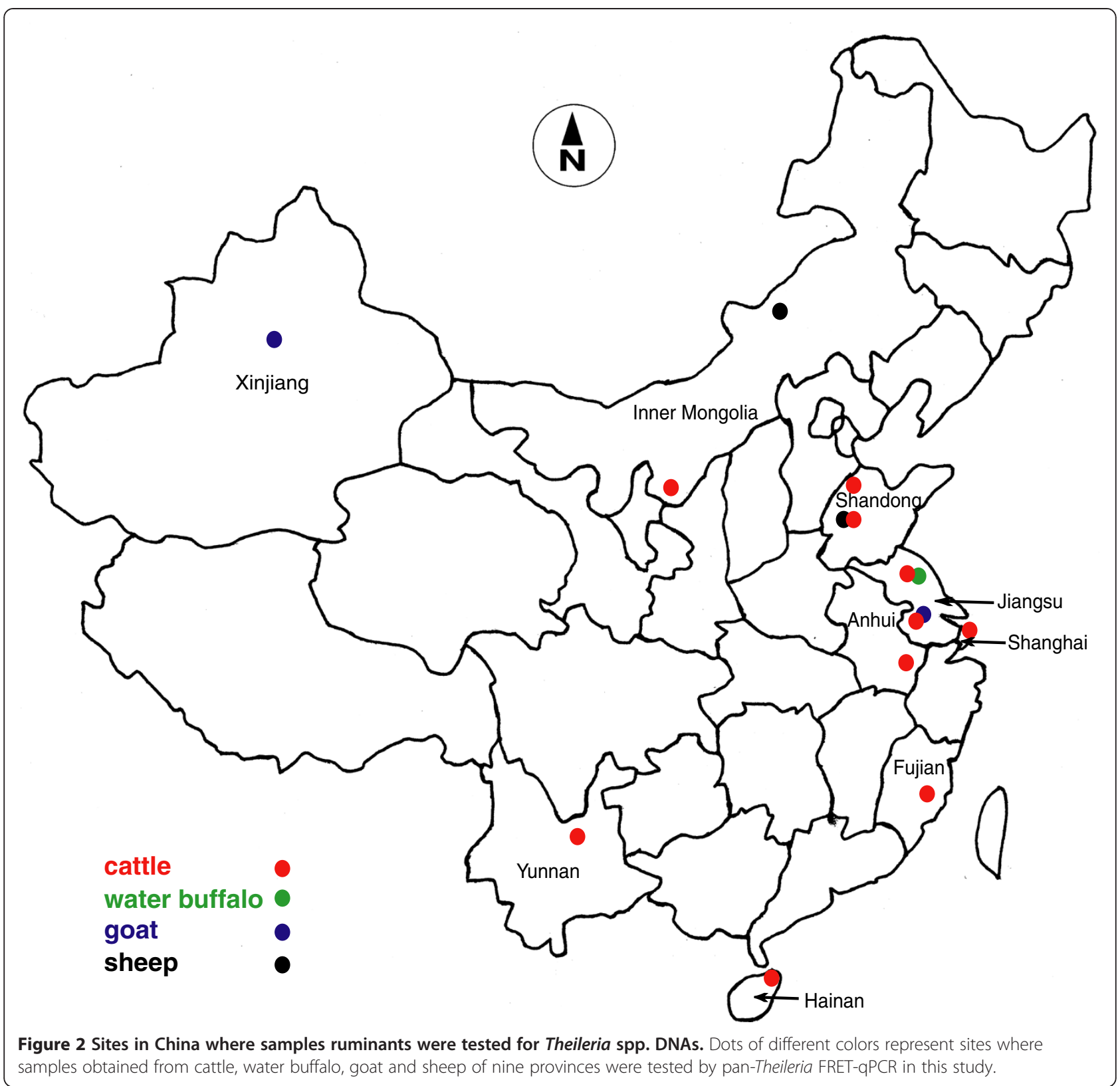

(65.2\% vs. $13.7 \% ; P<10^{-4}$ ) and have higher copy numbers of the Theileria $18 \mathrm{~S}$ rRNA gene $\left(10^{4.88}\right.$ vs. $10^{3.00}$ copies/ per ml whole blood; $\left.P<10^{-4}\right)$ than Bos $p$. taurus animals. The cattle from southern China had significantly higher Theileria $18 \mathrm{~S}$ rRNA gene copy numbers $\left(10^{4.39}\right.$ vs. $10^{3.87}$ copies/per $\mathrm{ml}$ whole blood; $P=0.02$ ) than those from northern China but this difference in the prevalence was not significant (31.8\% vs. $26.5 \%)$. In cattle from Yunnan province where gender information was available, female animals were more commonly positive $(76.7 \%$ vs. $41.3 \%$; $\left.P<10^{-4}\right)$ and copy numbers $\left(10^{5.02}\right.$ vs. $10^{2.93}$ Theilerial per ml whole blood; $P<10^{-4}$ ) than males.

\section{Gene accession numbers}

The Theileria rRNA nucleotide sequences obtained in this study that were not identical to existing entries in GenBank were deposited with the following gene accession numbers: KJ850933 and KJ850938 (T. sergenti); KJ850936 and KJ850940 (T. buffeli); KJ850934, KJ850937, KJ850943, KJ850939 and KJ850941 (T. orientalis); KJ850942 ( $T$. ovis); KJ850935 and KM016463 (T. luwenshuni). The sequences obtained were very similar (0-4 nucleotide mismatches) to Theileria spp. sequences deposited by other laboratories in China, USA, France, Australia and Iran (Table 2). 
Table 2 Comparison of isolates identified in this study and similar sequences in GenBank by BLASTN

\begin{tabular}{|c|c|c|c|c|c|}
\hline \multicolumn{3}{|c|}{ Isolates identified in this study } & \multicolumn{3}{|c|}{ Highly similar sequences in GenBank } \\
\hline Theileria spp. & Gene accession \# & Source/origin & Gene accession \# & Source/origin & Mismatches \\
\hline \multirow[t]{5}{*}{ T. orientalis } & KJ850934 & Simmental cattle, Inner Mongolia & AP011948 & Cattle, Shintoku of Japan & $0 / 547$ \\
\hline & KJ850939 & Luxi cattle, Shandong & HM538220 & Cattle, Suizhou of China & $0 / 547$ \\
\hline & KJ850937 & Yunling cattle, Yunnan & AB520956 & Cattle, New South Wales of Australia & $2 / 491$ \\
\hline & KJ850941 & Yunling cattle, Yunnan & AB520955 & Cattle, Raymond of Australia & $0 / 509$ \\
\hline & KJ850943 & Holstein cattle, Jiangsu & AB520956 & Cattle, New South Wales of Australia & $0 / 549$ \\
\hline \multirow[t]{2}{*}{ T. sergenti } & KJ850933 & Australian Holstein cattle, Jiangsu & JQ723015 & Cattle, Hunan of China & $0 / 541$ \\
\hline & KJ850938 & Yunling cattle, Yunnan & JQ723015 & Cattle, Hunan of China & $0 / 492$ \\
\hline \multirow[t]{2}{*}{ T. buffeli } & KJ850936 & Leiqiong cattle, Hainan & HM538196 & Cattle, Hubei of China; & $1 / 508$ \\
\hline & KJ850940 & Wannan cattle, Anhui & AY661513 & Cattle, USA & $0 / 545$ \\
\hline T. ovis & KJ850942 & Wuranke sheep, Inner Mongolia & FJ603460 & Sheep, Xinjiang of China; & $0 / 529$ \\
\hline \multirow[t]{2}{*}{ T. luwenshuni } & KJ850935 & from Sishui-Fur sheep, Shandong & $\begin{array}{l}\text { KC769996, JX469518, } \\
\text { JF719831 }\end{array}$ & Sheep, China & $0 / 549$ \\
\hline & KM016463 & $\begin{array}{l}\text { Yangtse River Delta White goat, } \\
\text { Jiangsu }\end{array}$ & KC769997 & Goat, Beijing of China & $0 / 571$ \\
\hline
\end{tabular}

\section{Discussion}

By systematically aligning the $18 \mathrm{~S}$ rRNA sequences of representative Theileria spp. and other related protozoa, we identified a highly conserved region to place primers and probes for a pan-Theileria FRET-qPCR. The primers and probes we designed enabled us to amplify all our reference Theileria species with a detection limit of at least 2 Theileria 18S rRNA gene copies per PCR system. None of the other protozoan species tested gave reaction products. To the best of our knowledge, this is the first FRET-qPCR which specifically detects all Theileria species.

Our data indicate infections with Theileria spp. are very widespread and common in cattle in China. We found positive animals in each province where we tested and an overall average of $30.77 \%$ of animals being positive. This relatively high level of positivity is similar to that obtained in the only other molecular survey for Theileria in China which showed $13.46 \%$ being positive in the northeast [32]. Sequencing data showed cattle are infected with the $T$. orientalis/T. sergenti/T. buffeli group which are generally recognized to be benign species [33] although some strains might cause economic losses [34].

Although we sequenced relatively few positive amplicons, we found no evidence of the more pathogenic strains, T. annulata and T. parva, which is not unexpected in the case of $T$. parva which has only been reported from Africa [8]. T. annulata, however, has been reported in $H$. asiaticum in northwestern China [35]. Our failure to demonstrate the organism in our study might be because $T$. annulata has an uneven distribution in China.

Although we found no evidence of Theileria spp. in the 29 water buffaloes we sampled, He [36] reported 58/
304 (19.1\%) positive for T. buffeli in Hubei province, south China. More extensive studies are necessary to determine the epidemiology of theileriosis in water buffaloes.

We found both goats and sheep were infected with $T$. luwenshuni (Table 2) using the pan-Theileria FRET-PCR and sequencing. This is a highly pathogenic organism that is known to occur in China where it is transmitted by Haemaphysalis qinghaiensis and may cause significant economic losses. While PCR assays have been described which detect and differentiate T. luwenshuni from $T$. uilenbergi $[37,38]$, they do not enable detection of all Theirleria spp. in all species and are thus not as versatile as our pan-Theileria FRET-PCR. Yin et al. [37] found the prevalence of T. luwenshuni varied from $0 \%$ to $85 \%$ in 4 provinces and we also found a wide range of positive values $(4.1 \%$ to $67.4 \%)$. Such variability is probably due to tick prevalence rates, geoclimatic factors and livestock management systems. Further research using sensitive detection methods will be important in determining the best mechanisms to control infections.

T. ovis was first identified in China in 2011 by PCR and sequencing and an infection rate of $78 \%$ was found in Xinjiang but no positive animals were found in twelve other provinces $[26,27,39]$. Our study confirms the presence of the organism in China although T. ovis is considered benign and economically unimportant as it might only cause signs in some animals which are stressed [40].

It is well recognized that exotic breeds are more susceptible to disease following infection with Theileria spp. than local stocks. Recent studies, however, have indicated that different breeds of animals might have similar susceptibilities to infections with Theileria spp. although 
some breeds are more capable of controlling the pathogenic effects of the organism [41].

Generally, B. p. taurus breeds are more susceptible to theileriosis than B. $p$. indicus breeds which might be associated with innate or immune mechanisms and/or general resistance to ticks. These factors have been mainly investigated with $T$. parva infections and thus it is interesting that our pan-Theileria FRET-PCR testing showed that in China it is the B. p. indicus breeds that are more likely to be positive than the $B$. $p$. taurus breeds and that the former generally had higher copy numbers indicating heavier infections. While our sample sizes were small and we cannot exclude the possibility of sample bias, our findings might be due to host genetic factors relating to infections with less pathogenic Theileria spp. or other factors such as differences in tick control and husbandry practices on different farms. Further studies taking these factors into account are needed to more precisely investigate the relationships between infections with benign Theileria spp. and the genetic background of the host.

\section{Conclusion}

In summary, our study has described the development and testing of a FRET-PCR which can detect recognized Theileria spp. The pan-Theileria FRET-PCR should be a useful diagnostic tool as it will enable diagnostic laboratories to detect infections in all domestic species with a single test.

\section{Competing interests}

The authors declare that they have no competing interests.

\section{Authors' contributions}

$C W, Y Y, Y M, Z Y$ and PK designed the study. YY, YM, ZY, LL, JL, JL and HSE performed the experiment. CW, YY and PK wrote the manuscript. All authors read and approved the final version of the manuscript.

\section{Acknowledgment}

This project was supported by grants from the National Natural Science Foundation of China (NO 31272575, 32472225), and by the Priority Academic Program Development of Jiangsu Higher Education Institutions.

\section{Author details \\ ${ }^{1}$ Jiangsu Co-innovation Center for the Prevention and Control of Important Animal Infectious Diseases and Zoonoses, Yangzhou University College of Veterinary Medicine, Yangzhou 225009, Jiangsu, China. ${ }^{2}$ Yangzhou University College of Animal Science and Technology, Yangzhou 225009, Jiangsu, China. ${ }^{3}$ Ross University School of Veterinary Medicine, Basseterre 00265, St. Kitts \& Nevis. ${ }^{4}$ Faculty of Veterinary Medicine, Suez Canal University, Ismailia 41225, Egypt.}

\section{Received: 3 July 2014 Accepted: 24 August 2014}

Published: 31 August 2014

\section{References}

1. Aktas M, Altay K, Dumanli N: PCR-based detection of Theileria ovis in Rhipicephalus bursa adult ticks. Vet Parasitol 2006, 140(3-4):259-263.

2. Morrison Wl: Progress towards understanding the immunobiology of Theileria parasites. Parasitology 2009, 136(12):1415-1426.

3. Muleya W, Namangala B, Simuunza M, Nakao R, Inoue N, Kimura T, Ito K, Sugimoto C, Sawa H: Population genetic analysis and sub-structuring of
Theileria parva in the northern and eastern parts of Zambia. Parasit Vectors 2012, 5:255.

4. Gachohi J, Skilton R, Hansen F, Ngumi P, Kitala P: Epidemiology of East Coast fever (Theileria parva infection) in Kenya: past, present and the future. Parasit Vectors 2012, 5:194.

5. Otranto D, Dantas-Torres F, Giannelli A, Latrofa MS, Cascio A, Cazzin S, Ravagnan S, Montarsi F, Zanzani SA, Manfredi MT, Capelli G: Ticks infesting humans in Italy and associated pathogens. Parasit Vectors 2014, 7:328. doi: 10.1186/1756-3305-7-328.

6. Balkaya I, Utuk AE, Piskin FC: Prevalance of Theileria equi and Babesia caballi in donkeys from Eastern Turkey in winter season. Pakistan Vet $J$ 2010, 30(4):245-246.

7. Hussain MH, Saqib M, Raza F, Muhammad G, Asi MN, Mansoor MK, Saleem M, Jabbar A: Seroprevalence of Babesia caballi and Theileria equi in five draught equine populated metropolises of Punjab, Pakistan. Vet Parasitol 2014, 202(3-4):248-256.

8. Muhanguzi D, Picozzi K, Hatendorf J, Thrusfield M, Welburn SC, Kabasa JD, Waiswa C: Prevalence and spatial distribution of Theileria parva in cattle under crop-livestock farming systems in Tororo District, Eastern Uganda. Parasit Vectors 2014, 7:91.

9. Razmi GR, Eshrati H, Rashtibaf M: Prevalence of Theileria spp. infection in sheep in South Khorasan province, Iran. Vet Parasitol 2006, 140(3-4):239-243.

10. Ros-García A, Nicolás A, García-Pérez AL, Juste RA, Hurtado A: Development and evaluation of a real-time PCR assay for the quantitative detection of Theileria annulata in cattle. Parasit Vectors 2012, 5:171.

11. Gomes J, Soares R, Santos M, Santos-Gomes G, Botelho A, Amaro A, Inácio J: Detection of Theileria and Babesia infections amongst asymptomatic cattle in Portugal. Ticks Tick Borne Dis 2013, 4(1-2):148-151.

12. Tian Z, Liu G, Yin H, Xie J, Wang S, Yuan X, Wang F, Luo J: First report on the occurrence of Theileria sp. OT3 in China. Parasitol Int 2014, 63(2):403-407.

13. McKeever DJ: Bovine immunity - a driver for diversity in Theileria parasites? Trends Parasitol 2009, 25(6):269-276.

14. Chen Z, Liu Q, Liu JQ, Xu BL, Lv S, Xia S, Zhou XN: Tick-borne pathogens and associated co-infections in ticks collected from domestic animals in central China. Parasit Vectors 2014, 7:237. doi: 10.1186/1756-3305-7-237.

15. Yang FG, Feng ZG, Yu GH, Liu JX, Wei ZQ, He XC: The report of sheep theileriosis in Ganning agriculture and animal husbandry station, Garze Tibetan Autonomous Prefecture. Chinese J Vet Med 1958, 2:33-37 (In Chinese)

16. Wang FX, Li O, Li W, Wang WX, Hua D, Wang LZ, Guo RM, Shi WZ, Li ZM Investigation of theileriosis in counties of Huangyuan, Menyuan and Jianzha. Chinese Qinghai J Animal Vet Sci 1980, 3:29-32 (In Chinese).

17. Li ZM, Hao YK, Chen TH, Yu XQ, Xi HL, Zuo YR, Chen YQ, Liu J, Ding YT, Meng ZX: The report of theileriosis of sheep in Dianan Commune, Longde county. Gansu Animal Vet Sci 1984, 1:13-14 (In Chinese).

18. Luo J, Yin H: Theileriosis of sheep and goats in China. Trop Anim Health Prod 1997, 29(4 suppl):S 8-S 10.

19. Guo S, Yuan Z, Wu G, Wang W, Ma D, Du H: Epidemiology of ovine theileriosis in Ganan region, Gansu Province, China. Parasitol Res 2002, 88(13 Suppl):S36-S37.

20. Guo SZ, Ma DL, Mou YJ, Yang SM, Wang WB, Ge GH, Ga DJ, Fang BQ: Epidemiological investigation of theileriosis in goats and sheep in northern China. Chinese J Vet Parasitol 2005, 4:15-17 (In Chinese).

21. Yuan YQ, Li YQ, Liu ZJ, Yang JF, Chen Z, Guan GQ, Luo JX, Yin H: Epidemiological investigation of theileriosis in goats and sheep in southern China. Chinese Vet Sci 2013, 43:551-556 (In Chinese).

22. Hu SY, Zhang SF, Qian NC, Jia LJ, Xue SJ, Sun KN, Lin WJ: Molecular epidemiological survey of Theileria sergenti infection in cattle in part areas of Jilin province. Chinese J Prev Vet Med 2013, 35:539-541 (In Chinese).

23. Jian ZJ, Ma SZ, Sun QZ, Shen JY, Lv W, Miao ZQ: Epidemiologic survey for detection of Theileria annulata-infected cattle in Xinjiang by an improved indirect tams1 ELISA assay. Xinjiang Agric Sci 2011, 48:1509-1513 (In Chinese).

24. Kahar S, Cao WL, Zhang Y, Wang BJ, Bayinchahan: Epidemiological investigation of infection of Theileria annulata for cattle in some epidemic areas of Turpan. Xinjiang Agric Sci 2013, 50:1161-1164 (In Chinese).

25. Li Y, Chen Z, Liu Z, Liu J, Yang J, Li Q, Li Y, Cen S, Guan G, Ren Q, Luo J, Yin H: Molecular identification of Theileria parasites of Northwestern Chinese Cervidae. Parasit Vectors 2014, 7(1):225.

26. Ge Y, Pan W, Yin H: Prevalence of Theileria infections in goats and sheep in Southeastern China. Vet Parasitol 2012, 186(3-4):466-469. 
27. Li Y, Zhang X, Liu Z, Chen Z, Yang J, He H, Guan G, Liu A, Ren Q, Niu Q, Liu J, Luo J, Yin H: An epidemiological survey of Theileria infections in small ruminants in central China. Vet Parasitol 2014, 200(1-2):198-202.

28. Sambrook J: Molecular Cloning: A Laboratory Manual. New York: Cold Spring Harbor Laboratory; 1989.

29. Wei L, Kelly P, Zhang J, Yang Y, Zheng X, Tao J, Zhang Z, Wang C: Use of a universal hydroxymethylbilane synthase (HMBS)-based PCR as an endogenous internal control and to enable typing of mammalian DNAs. Appl Microbiol Biotechnol 2014, 98:5579-5587. doi: 10.1007/s00253-014-5659-X.

30. Wang C, Mount J, Butler J, Gao D, Jung E, Blagburn BL, Kaltenboeck B: Real-time PCR of the mammalian hydroxymethylbilane synthase (HMBS) gene for analysis of flea (Ctenocephalides felis) feeding patterns on dogs. Parasit Vectors 2012, 5:4. doi: 10.1186/1756-3305-5-4.

31. Jefferies R, Ryan UM, Irwin PJ: PCR-RFLP for the detection and differentiation of the canine piroplasm species and its use with filter paper-based technologies. Vet Parasitol 2007, 144(1-2):20-27.

32. Yu L, Zhang $S$, Liang $W$, Jin C, Jia L, Luo Y, Li Y, Cao S, Yamagishi J, Nishikawa Y, Kawano S, Fujisaki K, Xuan X: Epidemiological survey of Theileria parasite infection of cattle in northeast China byallele-specific PCR. J Vet Med Sci 2011, 73(11):1509-1512.

33. Kamau J, de Vos AJ, Playford M, Salim B, Kinyanjui P, Suqimoto C: Emergence of new types of Theileria orientalis in Australian cattle and possible cause of theileriosis outbreaks. Parasit Vectors 2011, 4:22.

34. McFadden AM, Rawdon TG, Meyer J, Makin J, Morley CM, Clough RR, Tham K, Mullner P, Geysen D: An outbreak of haemolytic anaemia associated with infection of Theileria orientalis in naive cattle. N Z Vet J 2011, 59(2):79-85.

35. Meng K, Li Z, Wang Y, Jing Z, Zhao X, Liu J, Cai D, Zhang L, Yang D, Wang S: PCR-based detection of Theileria annulata in Hyalomma asiaticum ticks in northwestern China. Ticks Tick Borne Dis 2014, 5(2):105-106.

36. He L, Feng HH, Zhang WJ, Zhang QL, Fang R, Wang LX, Tu P, Zhou YQ, Zhao JL, Oosthuizen MC: Occurrence of Theileria and Babesia species in water buffalo (Bubalus babalis, Linnaeus, 1758) in the Hubei province, South China. Vet Parasitol 2012, 186(3-4):490-496.

37. Yin H, Liu Z, Guan G, Liu A, Ma M, Ren Q, Luo J: Detection and differentiation of Theileria luwenshuni and T. uilenbergi infection in small ruminants by PCR. Transbound Emerg Dis 2008, 55(5-6):233-237.

38. Zhang X, Liu Z, Yang J, Chen Z, Guan G, Ren Q, Liu A, Luo J, Yin H, Li Y: Multiplex PCR for diagnosis of Theileria uilenbergi, Theileria luwenshuni, and Theileria ovis in small ruminants. Parasitol Res 2014, 113(2):527-531.

39. Li Y, Guan G, Ma M, Liu J, Ren Q, Luo J, Yin H: Theileria ovis discovered in China. Exp Parasitol 2011, 127(1):304-307.

40. Ahmed J, Yin H, Bakheit M, Liu Z, Mehlhorn H, Seitzer U: Small ruminant theileriosis. Parasitol Res Monograph 2011, 2:135-153.

41. Ndungu SG, Brown CG, Dolan TT: In vivo comparison of susceptibility between Bos indicus and Bos taurus cattle types to Theileria parva infection. Onderstepoort J Vet Res 2005, 72(1):13-22.

doi:10.1186/1756-3305-7-413

Cite this article as: Yang et al:: A pan-Theileria FRET-qPCR survey for Theileria spp. in ruminants from nine provinces of China. Parasites \& Vectors 2014 7:413.

\section{Submit your next manuscript to BioMed Central and take full advantage of:}

- Convenient online submission

- Thorough peer review

- No space constraints or color figure charges

- Immediate publication on acceptance

- Inclusion in PubMed, CAS, Scopus and Google Scholar

- Research which is freely available for redistribution 